\title{
Redesigning the Landscape for Women and Leadership: Insights Gained from the Covid-19 Pandemic. On Behalf of Women in Gastroenterology Network Asia Pacific (WIGNAP) and Women in Endoscopy (WIE)
}

\author{
Lubna Kamani ${ }^{1}$, Nonthalee Pausawasdi ${ }^{2}$, Jeanin E.Van Hooft ${ }^{3}$, Amrita Sethi ${ }^{4}$ and Sharmila Sachithanandan ${ }^{5}$ \\ ${ }^{1}$ Liaquat National Hospital and Aga Khan University Hospital, Karachi, Pakistan, ${ }^{2}$ Siriraj Hospital, Mahidol University, Bangkok, \\ Thailand, ${ }^{3}$ Leiden University Medical Center, Leiden, The Netherlands, ${ }^{4}$ Columbia University Irving Medical Center, New York, NY, \\ USA, ${ }^{5}$ Ramsay Sime Darby Medical Center, Kuala Lumpur, Malaysia
}

The year 2020 will be remembered for the catastrophic Covid-19 pandemic that swept across the world, leaving in its path an epic level of lives lost and economic despair that has rarely been seen in this century. During this International disaster, Taiwan, New Zealand, Germany, Finland, Iceland, Norway and Denmark, countries all helmed by women, stood out on the global stage for having dealt with the ravages of the global pandemic most effectively. ${ }^{1}$ Is this pairing of female leadership and successful shielding from the pandemic's potential destruction sheer coincidence or rather a testimony to the innate leadership qualities possessed by women, unveiled during times of crisis?

Spanning Scandinavia to the Asia-Pacific region, these female leaders, including the Health Minister of the State of Kerala, India, KK Shailaja and Jung Eun-Kyeong, Director of the Korea Centers for Disease Control and Prevention (KCDC), South Korea emerged from the pandemic as "heroines" because they took swift, decisive action to fight the disease. They courageously led their countries to "go hard, go early", as stated by Jacinda Arden, Prime Minister of New Zealand. ${ }^{2}$ They carried out costly interventions at considerable personal political

Received: July 28, 2020 Revised: September 6, 2020

Accepted: September 6, 2020

Correspondence: Sharmila Sachithanandan

Ramsay Sime Darby Medical Center, Kuala Lumpur, Malaysia

Tel: +60-1-2606-8979, Fax: +60-3-5639-1380, E-mail: sharmilasachi68@gmail.com

ORCID: https://orcid.org/0000-0001-7033-3992

(cc) This is an Open Access article distributed under the terms of the Creative Commons Attribution Non-Commercial License (http://creativecommons.org/ licenses/by-nc/3.0) which permits unrestricted non-commercial use, distribution, and reproduction in any medium, provided the original work is properly cited. risk by instituting aggressive, large scale national testing and contact tracing programs. Practicing the "lives before livelihood" mantra, and unapologetically prioritizing the health, safety, and well-being of their citizens over their plunging economies, they demonstrated tender yet pragmatic compassion associated with maternal survival instincts. ${ }^{2}$ Women led countries suffered only one sixth of the death toll when compared to countries governed by men. The former is also more likely to rapidly recover from an economic recession. ${ }^{1}$ In the business world, the practice of recruiting women into leadership roles during periods of extreme stress and high risk of failure, is known as the "glass cliff". It has been predicted that even after attaining leadership roles, they continue to face gender biases resulting in heightened scrutiny and criticism. They are also treated differently from their male counterparts in these roles and face unprecedented challenges in attaining and sustaining leadership positions. Implied in this phenomenon is the transient need for these leadership styles and finite benefits applicable only in moments of crisis. The successful outcomes of this type of governance suggest that elevating women to leadership positions during "normal" times would have tremendous impact.

When appraising why female leaders were so effective during this crisis, they collectively demonstrated some prominent traits. Recognizing the necessity for accountability, these women demonstrated strength, adaptability, perseverance, grit, empathy, passion and tenacity. Together they were thoughtful, intentional, consultative, inclusive and deliberate in their leadership styles. The most essential element for women leading health care systems is the drive for equity, challenging status 
quos and norms, and building a common vision of health by listening. They integrated input from scientists, public health epidemiologists and infectious disease experts, demonstrating humility rather than procrastinating difficult decisions and surrounding themselves exclusively with sycophantic political allies. They universally provided continuous, transparent updates with candid and concise explanations that outlined the rationale behind their strategies, thus engaging their citizens' trust and compliance with their national policies. Jacinda Arden's "Be Kind" phrase and the Children's conference held by Norway's Erna Solberg are examples of empathetic attempts to acknowledge and speak to their constituents' humanity. These women broke the erroneous stereotypes of youth and femininity being acquainted with inexperience, weakness, or immaturity. In leading by example, these women served as great role models and sources of inspiration.

We do not have to look exclusively at the world stage to see manifestations of the "glass cliff". In the words of Soumya Swaminathan, Chief scientist at the World Health Organization (WHO) "it is an opportunity for a spotlight on the role of women at home that often goes unrecognized, unappreciated and not reimbursed, as well as women in the work settings who are at the frontline. It is women who are carrying this burden". Women comprised majority of the world's frontline healthcare workers, shouldering the burden of strenuous work and putting themselves at high risk of infection. Despite the physical and psychological tolls of contracting infection, facing mortality, and isolating themselves from their families, these women did not retreat when called upon to serve.

Another lesson learned from the crisis was the feasibility and success of a redrawing of gender roles while at home. The increasing global digitization and connectivity expedited by Covid-19, together with creative technology-driven strategies, allowed for managing work and personal responsibilities equally for men and women. Not only did the pandemic expose the need for increased work-life balance policies, it also demonstrated the value of creative, innovative solutions with flexible training and working from home, with no detriment to quality outcomes and productivity. Jang et al. elaborated work-life balance among Korean gastroenterologists, reporting more burnout and work life imbalance among young women doctors. ${ }^{4}$ They spent more hours with their family doing household chores as compared to men while holding same academic position. Women doctors also reported a lack of support from their husbands/partners. ${ }^{4}$ Female speakers have been shown to be underrepresented at medical conferences, decline promotion opportunities and are less likely to achieve full time professorship. ${ }^{5}$ Based on these observations, an important question arises- Are men blocking women or women blocking themselves? This is a perplexing and complicated issue without straightforward solutions. For a holistic approach, various nations need to devise their own strategies based on their local government/societal guidelines, creating the support system while taking into account cultural norms. By adopting a pragmatic approach and expanding options for managing work and family life, women may gain workplace equality with men.

As we emerge from the Covid-19 "era", we are faced with many questions regarding the "new normal". Another, which is relevant to this discussion, is whether we can redesign the landscape of the role of women and leadership from the global stage to the common workplace? The pandemic has proven to the skeptical observer that women can lead successfully. It has also shown us that many of these women are from countries that rank high on the Global Gender Gap 2020 report and are supported by progressive societies. ${ }^{6}$ The outcomes achieved, of unity, preservation of lives (or health), inclusivity, and minimization of disruption, among others, are goals that we can envisage to achieve in all settings from all types of leaders. To effect change, however, there must be support from within.

These realizations are particularly relevant in medicine where women have notoriously had poor representation in the leadership positions. Although $70 \%$ of the worlds' healthcare staff are women, $50 \%$ of these are nurses and midwives. Despite the majority of the health workforce comprising of women, only a quarter are at the table of experts and in senior leadership roles making impactful critical decisions. ${ }^{7}$ An analysis of 104 countries showed that approximately $70 \%$ of health and social sector workers are women. The Americas (86\%), Europe (84\%) and Western Pacific (81\%) are regions with highest proportion of women being nurses. ${ }^{8}$ Women are substantially underrepresented in the leadership positions in most of the medical specialties. As in any Interventional related field, Gastroenterology also holds male predominance and women gastroenterologists find it difficult to get leadership roles. They earn less, have fewer children or remain childless and overall receive compromised advanced endoscopy training. ${ }^{9}$ A study conducted by Rembacken at al explictly pointed out that patriarchy, lack of self-advocacy, child bearing issues, women working part time and lack of confidence are the main barriers behind women's induction in advanced endoscopy training programs. ${ }^{10}$ In medical schools, women faculty engage in less than $50 \%$ of combined leadership roles, i.e., department chairs, program directors, and division chiefs. The factors that hinder women's leadership emergence and enactment can be at an institutional level, such as research production requirement, educational background and policy development, or at an interpersonal level, including lack of mentorship and gen- 
der bias. Issues surrounding the balance of family life, such as childbearing or care for the elderly, have traditionally served as barriers to leadership, can now be mitigated by adopting strategies that incorporate greater work-life balance. Furthermore, the approaches to promoting women in leadership roles must include cultural changes in stereotyping, implementation of gender equality policies, and access to mentoring programs and sponsors. In an environment where leaders dictate the flow of funding and research, the presence of women is imperative to ensure that gender issues will be adequately addressed, whether in a state of crisis or during normal conditions.

After examining the lessons learned by the exemplary performances of women leaders during the pandemic, it seems that in envisioning the "new normal", we may step off the "glass cliff" onto a new "high road" with infinite possibilities for success and growth in the future. Societies and organizations should choose champion leaders based solely on their capabilities and visions irrespective of gender, ethnicity, or creed. The repercussions of the coronavirus crisis will be global and enduring. Nonetheless, they also offer a tremendous opportunity to shape our personal and professional working lives differently with hope for a better, more sustainable future.

Conflicts of Interest

The authors have no financial conflicts of interest.

Author Contributions

Conceptualization: Lubna Kamani

Investigation: LK, Nonthalee Pausawasdi, Sharmila Sachithanandan

Methodology: LK, SS

Project administration: LK

Resources: NP, SS

Supervision: LK, Jeanin E.Van Hooft, Amrita Sethi

Visualization: NP, JEVH, AS, SS

Writing-original draft: SS

Writing-review\&editing: LK, NP, JEVH, AS

\section{Acknowledgment}

We would like to acknowledge the support of the following during the compilation of the manuscript. Dr. Majidah Bukhari (International Medical Center, Jeddah, Saudia Arabia), Prof. Eun Young Kim (Daegu Catholic University Hospital, South Korea), Dr. Nazish Butt (Jinnah Post Graduate Center, Karachi, Pakistan), Prof. Bushra Jamil (Aga Khan University Hospital,
Karachi, Pakistan), Dr. Simone Guaraldi (Instituto Nacional de Cancer, Rio de Janeiro, Brazil), Dr. Payal Saxena (Royal Prince Alfred Hospital, Sydney, Australia), Dr. Reiko Ashida (Wakayama Medical University, Japan).

ORCID

Lubna Kamani: https://orcid.org/0000-0003-2651-5179

Nonthalee Pausawasdi: https://orcid.org/0000-0002-3737-8555

Jeanin E.Van Hooft: https://orcid.org/0000-0002-4424-0079

Amrita Sethi: https://orcid.org/0000-0001-7989-0242

\section{REFERENCES}

1. Fioramonti L, Coscieme L, Trebeck K. Women in power: it's a matter of life and death [Internet]. London: Social Europe; c2020 [updated 2020 Jun 1]. Available from: https://www.socialeurope.eu/women-in-powerits-a-matter-of-life-and-death.

2. Hickey B. We must go hard and we must go early [Internet]. Wellington: Newsroom; c2020 [updated 2020 Aug 14]. Available from: https://www. newsroom.co.nz/2020/03/14/1083045/we-must-go-hard-and-we-mustgo-early.

3. Ryan MK, Haslam SA. The glass cliff: evidence that women are over-represented in precarious leadership positions. British Journal of Management 2005;16:81-90.

4. Jang ES, Park SM, Park YS, Lee JC, Kim N. Work-life conflict and its health effects on Korean gastroenterologists according to age and sex. Dig Dis Sci 2020;65:86-95.

5. Blumenthal DM, Olenski AR, Yeh RW, et al. Sex differences in faculty rank among academic cardiologists in the United States. Circulation 2017; 135:506-517.

6. World Economic Forum. Global gender gap report 2020 [Internet]. Cologny/Geneva: World Economic Forum; c2019 [updated 2019 Dec 17]. Available from: http://www3.weforum.org/docs/WEF_GGGR_2020. pdf.

7. Women Political Leaders. World Health Day 2020- where are the female healthcare leaders? [Internet]. Reykjavík: Women Political Leaders; c2020 [updated 2020 Apr 7]. Available from: https://www.womenpoliticalleaders.org/world-health-day-2020-where-are-the-female-healthcare-leaders/.

8. Boniol M, McIsaac M, Xu L, Wuliji T, Diallo K, Campbell J. Gender equity in the health workforce: analysis of 104 countries [Internet]. Geneva: World Health Organization; c2019 [updated 2019 Mar]. Available from: https://apps.who.int/iris/bitstream/handle/10665/311314/WHOHIS-HWF-Gender-WP1-2019.1-eng.pdf?sequence=1\&isAllowed=y.

9. Cochran A, Hauschild T, Elder WB, Neumayer LA, Brasel KJ, Crandall ML. Perceived gender-based barriers to careers in academic surgery. Am J Surg 2013;206:263-268.

10. Rembacken BJ, Dixon S, Albuquerque A, Fairbrass K, Pana M. Barriers and bias standing in the way of female trainees wanting to learn advanced endoscopy. United European Gastroenterol J 2019;7:1141-1145. 